\title{
Sensory deficits of a nerve root lesion can be objectively documented by somatosensory evoked potentials elicited by painful infrared laser stimulations: a case study
}

\author{
J Lorenz, H C Hansen, K Kunze, B Bromm
}

Institute of Physiology J Lorenz

B Bromm

Neurological

Department of

University Hospital

Eppendorf, Hamburg,

Germany

H C Hansen

K Kunze

Correspondence to:

Institute of Physiology,

University Hospital

Eppendorf, Martinistraße 52, 20246 Hamburg, Germany.

Received 25 September 1995 and in revised form

Accepted 16 February 1996
Professor Dr B Bromm,

24 January 1996

\section{Abstract}

Somatosensory evoked potentials (SEPs) in response to painful laser stimuli were measured in a patient with a unilateral sensory deficit due to radiculopathy at cervical levels C7 and C8. Laser evoked potentials (LEPs) were compared with SEPs using standard electrical stimulation of median and ulnar nerves at the wrist and mechanical stimulation of the fingertips by means of a mechanical stimulator. Early and late ulnar and median nerve SEPs were normal. Mechanical stimulation resulted in $w$ shaped early SEPs from all five fingertips with some degree of abnormality at the fourth and fifth digits of the affected hand. Late LEPs were completely absent for stimulations at affected dermatomes and normal in the unaffected control dermatomes. The border between skin areas with normal or absent LEPs was very sharp and fitted the

Sensory testing results of affected (C7/C8) and non-affected (C6) dermatomes

\begin{tabular}{|c|c|c|}
\hline $\begin{array}{l}\text { Sensory quality and } \\
\text { tested function method }\end{array}$ & $\begin{array}{l}\text { Affected dermatome } \\
\text { C7/C8 }\end{array}$ & $\begin{array}{l}\text { Non-affected dermatome } \\
\text { C6 }\end{array}$ \\
\hline \\
\hline $\begin{array}{l}\text { Pressure threshold }(\mathrm{PT}) \\
v \text { Frey filaments }\end{array}$ & 1 & 2 \\
\hline $\begin{array}{l}\text { Vibration threshold (VT) } \\
128 \mathrm{~Hz} \text { tuning fork; } \\
8 / 8 \text { scaled }\end{array}$ & 1 & 2 \\
\hline Light touch & 0 & 2 \\
\hline $\begin{array}{l}\text { cotton wool stabs } \\
\text { Joint position sense } \\
\text { passive finger/toe } \\
\text { movements }\end{array}$ & 0 & 2 \\
\hline M score (\%) & 25 & 100 \\
\hline \multirow{5}{*}{$\begin{array}{l}\text { Temperature sensitivity: } \\
\text { Warm sense } \\
43^{\circ} \mathrm{C}: \text { short }=0.5 \mathrm{~s} \\
\text { Warm sense } \\
43^{\circ} \mathrm{C}: \text { long }=3 \mathrm{~s} \\
\text { Cold sense } \\
22^{\circ} \mathrm{C}: \text { short }=0.5 \mathrm{~s} \\
\text { Cold sense } \\
22^{\circ} \mathrm{C}: \text { long }=3 \mathrm{~s} \\
\text { T score }(\%)\end{array}$} & 0 & 2 \\
\hline & 0 & 2 \\
\hline & 0 & 2 \\
\hline & 0 & 2 \\
\hline & 0 & 100 \\
\hline $\begin{array}{l}\text { Pain sensitivity: } \\
\text { Mechanical pain }\end{array}$ & 0 & 2 \\
\hline $\begin{array}{l}\text { pulling a hair } \\
\text { Mechanical pain }\end{array}$ & 0 & 2 \\
\hline $\begin{array}{l}\text { pin prick } \\
\text { Sharp blunt } \\
\text { discrimination } \\
\text { Safety pin }\end{array}$ & 0 & 2 \\
\hline $\begin{array}{l}\text { Safety pin } \\
\text { Heat pain threshold (HPT) } \\
\text { CO laser }\end{array}$ & 0 & 2 \\
\hline $\begin{array}{l}\mathrm{CO}_{2} \text { laser } \\
\mathrm{P} \text { score }(\%)\end{array}$ & 0 & 100 \\
\hline
\end{tabular}

$0=$ not perceived; $1=$ disturbed; $2=$ normal. (PT) $0=>275 \mathrm{~g} ; 1=0.8 \mathrm{~g}-275 \mathrm{~g} ; 2=<0.8$ (VT) $0=\langle 1 / 8 ; 1=1 / 8-4 / 8 ; 2=>4 / 8$. (HPT) $0=>30 \mathrm{~W} ; 1=18 \mathrm{~W}-30 \mathrm{~W} ; 2=<18 \mathrm{~W}$. dermatomes of intact $\mathrm{C} 6$ and damaged $\mathrm{C} 7$ and C8 nerve roots. It is suggested that pain dermatomes are narrower than tactile dermatomes because thin fibres of the nociceptive system, activated by laser stimuli, probably do not overlap between adjacent spinal segments to the same extent as thick fibres of the mechanoreceptive system, activated by standard electrical or mechanical stimulation.

\section{$(尹$ Neurol Neurosurg Psychiatry 1996;61:107-110)}

Keywords: radiculopathy; laser evoked potentials; somatosensory evoked potentials; mechanical stimulation; electrical stimulation

Verification and topodiagnosis of nerve root affections usually cause no problem if sensory and motor signs indicate the same segment and the motor axonal damage can be proved by EMG. However, evaluation of the sensory deficit completely relies on the patient's report so that in cases of isolated dorsal root affection or incongruent motor and sensory signs there is a need for objective methods regarding the sensory component. Standard electrical somatosensory evoked potentials (SEPs) can fail to document the sensory deficit. ${ }^{1-3}$ We present a patient with a unilateral sensory deficit in $\mathrm{C} 7$ and C8 dermatomes. Objective verification of the border between areas of normal and affected skin sensitivity was achieved by means of late SEPs in response to painful radiant heat stimuli delivered by a $\mathrm{CO}_{2}$ laser. This infrared laser selectively activates superficial $\mathrm{A} \delta$ and $\mathrm{C}$ fibres of the nociceptive system and has been previously reported as an appropriate tool to examine the functional integrity of peripheral small fibres and anterolateral tracts. ${ }^{4-6}$

\section{Patient and methods}

MEDICAL HISTORY AND CLINICAL FINDINGS

This 65 year old man complained about cervical pain and brachialgia in his right arm that had started some five years previously. For seven months he had noted numbness without paraesthesia of the ulnar portion of the forearm and the hand and loss of grip strength. Particularly, the fifth digit was reported to be 
Figure 1 Computed axial tomography shows hypodense disc material protruding into the vertebral canal and right neuroforamen. The scan corresponds to the level between $C 7$ and Th1 vertebrae.

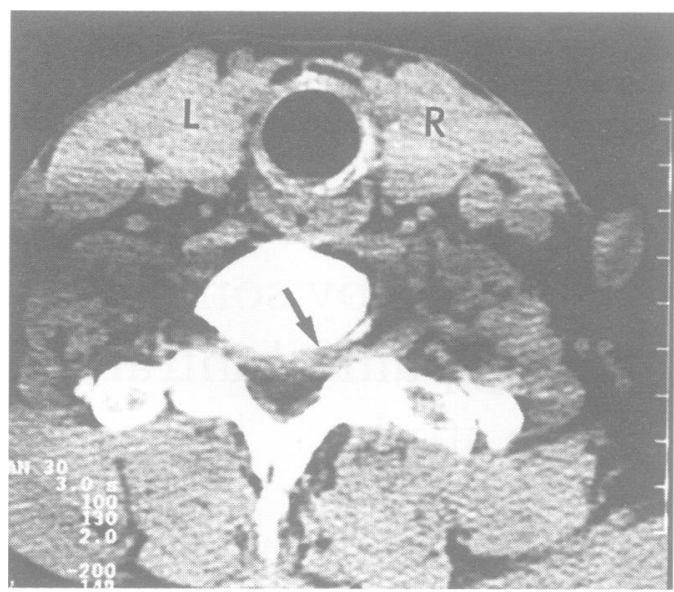

“dead". Neurological examination disclosed painful immobility of the cervical spine with spontaneous head tilt towards the right. Strength examination disclosed moderate paresis (MRC grade 4) of right wrist extensors and interossei without atrophy. Tendon reflexes of triceps muscles were slightly reduced on both sides. Strength and tendon reflexes of other muscles were normal.

The sensory deficit was determined according to a standard protocol (see table) ${ }^{5}$ that tested for mechanosensitivity ( $M$ score), temperature sensitivity ( $\mathrm{T}$ score), and pain sensitivity ( $\mathrm{P}$ score). Four subtests of each sensory quality were scored on a three point scale: normal ( 2 points), disturbed ( 1 point), and absent (0 points). The sum scores were normalised to percentage of maximum value. Within affected C7 and C8 dermatomes there was a complete loss of temperature and pain sensitivity and a $25 \%$ residual mechanosensitivity due to the patient's ability to perceive vibration at $2 / 8$ when stimulated with an $8 / 8$ scaled $128 \mathrm{~Hz}$ tuning fork and to perceive pressure of calibrated von Frey nylon monofilaments at $164 \mathrm{~g}$. Normal sensitivity was present in the non-affected C6 dermatome. The clinical findings were regarded as consistent with radiculopathy in right $\mathrm{C} 7$ and $\mathrm{C} 8$ vertebrae due to spondylosis.
NEUROPHYSIOLOGICAL ASSESSMENT

Laser evoked potentials (LEPs) were elicited as published previously. ${ }^{4}$ In summary, cutaneous radiant heat stimuli delivered by a $\mathrm{CO}_{2}$ laser were applied to the dorsal skin of affected and non-affected dermatomes. Laser intensities of $20 \mathrm{~W}(20 \mathrm{~ms}$ duration; $5 \mathrm{~mm}$ beam diameter) were used which is above normal pain threshold $\left(10 \cdot 0\right.$ (SD 2.3) W). ${ }^{7}$ Electrical nerve stimuli were also randomly interspersed between laser stimuli which served to evaluate late SEPs. Two blocks of 60 stimulations at both control and affected dermatomes were repeated. An EEG was recorded within 0.1 and $30 \mathrm{~Hz}$ over $\mathrm{Cz}$ and averaged according to stimulus modality (electrical $v$ laser) and stimulated dermatome (affected $v$ nonaffected).

Conventional early cortical SEPs were recorded using electrical stimulation $(3 \mathrm{~Hz}$ repetition rate, $0.3 \mathrm{~ms}$ duration, constant current) of median and ulnar nerves at the wrist of the affected hand. Stimulus intensity was adjusted to the sum of sensory and motor threshold. The EEG was recorded within 10 and $1000 \mathrm{~Hz}$ at electrode positions over the somatosensory projection area against $\mathrm{Fz}$ reference. A total of 256 artefact free poststimulus epochs of $100 \mathrm{~ms}$ duration were digitised at $3000 \mathrm{~Hz}$ and averaged on line. The N20 component was compared with normal height corrected values from our laboratory.

Early cortical SEPs were additionally elicited at all five finger tips of the affected hand by a mechanical stimulator (Somedic TS 120) which had a $10 \mathrm{~mm}$ diameter stimulating probe with nine blunt tips, each with a diameter of $2 \mathrm{~mm}$. The patient's stimulated finger rested on the probe, which was displaced by $500 \mu \mathrm{m}$ with a slope of $1000 \mu \mathrm{m} / \mathrm{ms}$ at a stimulus rate of $2 \mathrm{~Hz}$ and a duration of $2 \mathrm{~ms}$. This stimulation did not cause a movement of the finger. Previous experiments with the mechanical stimulator on normal subjects in our laboratory (unpublished data) have proved this setting appropriate to reliably elicit $w$ shaped primary cortical responses consisting of N28P35, likely to correspond to N20 and P27 of

\section{Laser evoked potentials}
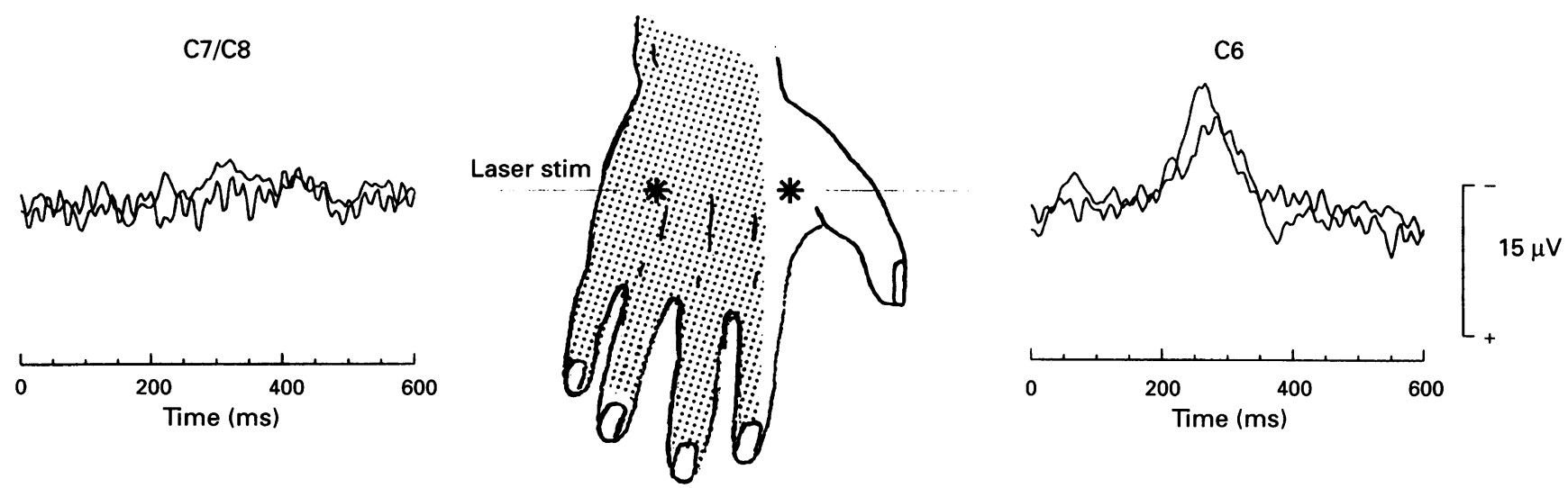

Figure 2 Laser evoked potentials are absent after stimulation of affected C7/C8 dermatomes (shaded area) and normal after stimulation of non-affected C6 dermatome. 

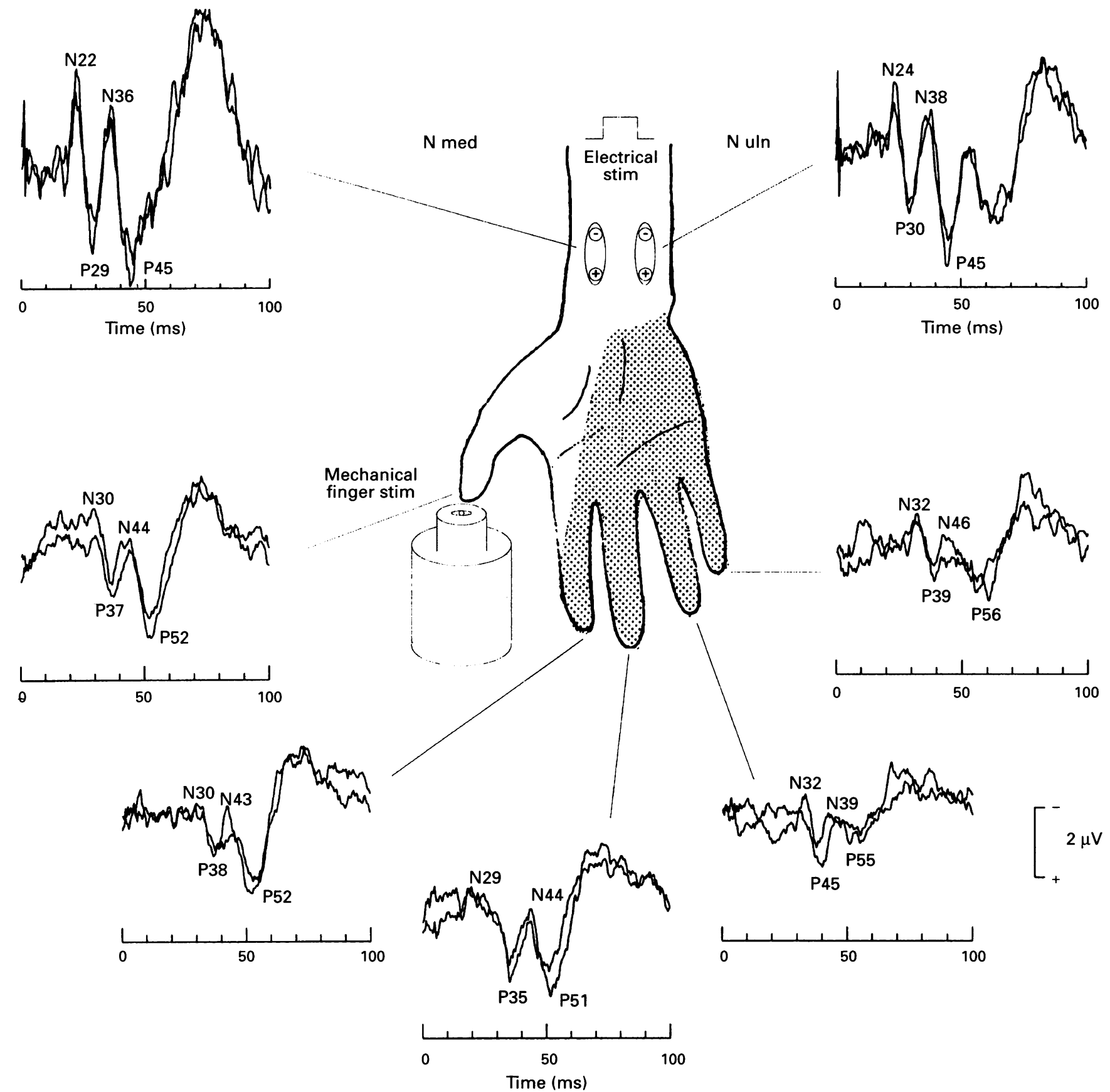

Time (ms)

Figure 3 Early somatosensory evoked potentials (SEPs) after electrical stimulation of right median (top left) and ulnar nerves (top right) and after mechanical stimulation with pressure pulses of all five digits at the fingertips of the right hand. The shaded area indicates the extent of the sensory deficit within C7/C8 dermatomes. Electrical SEPs are normal. Mechanical SEPs yield poor configuration and latency delay of P50 at the fourth and fifth digits respectively.

electrical stimulation, ${ }^{8}$ and a pronounced P50 component, assumed to be identical with the P50 of Hämäläinen et al using mechanical pulses. ${ }^{9}$ The EEG recording parameters were identical with those of electrical SEP recordings. Headphones with white noise masked any sound from the stimulator.

\section{Results}

Needle EMG with semiquantitative motor unit potential (MUP) evaluation disclosed high amplitude MUPs (up to $4 \mathrm{mV}$ ) in the right extensor carpi radialis, extensor digitorum, extensor carpi ulnaris, interosseus dorsalis I, and paraspinals $\mathrm{C} 7 / \mathrm{C} 8$, but not in biceps and brachioradialis. Fibrillation poten- tials were absent in tested muscles. These results were considered to be consistent with a radiculopathy involving right $\mathrm{C} 7$ and $\mathrm{C} 8$ roots. Radiological studies of the cervical spine showed spondylosis between vertebrae $\mathrm{C} 6 / \mathrm{C} 7$ and $\mathrm{C} 7 / \mathrm{Th} 1$. Computed tomography disclosed narrowing in the right intervertebral nerve root canal at level CV 6/7 (fig 1). The lower adjacent segment was partly obscured by bone artifacts. An MRT was not available. Anatomical findings were consistent with a cervical spondylosis and suggested compression of the right nerve root $\mathrm{C} 7$.

The shaded area in fig 2 shows the extent of sensory deficit at the hand dorsum. Laser evoked potentials were absent for stimuli applied to the shaded skin areas, whereas 
normal LEPs were elicited after stimulation of the non-shaded area. Thus LEPs confirmed clinical analgesia and thermanaesthesia and indicated very sharply the border between dermatomes of affected and non-affected cervical roots.

Figure 3 gives the results of early SEPs after electrical stimulation of median and ulnar nerves at the wrist and after mechanical stimulation of all five digits of the affected hand in this patient. Early electrical SEPs were well elicited from median and ulnar nerves as typical w shaped configurations. Latencies of N22 (median nerve) and N24 (ulnar nerve) were normal according to our standards. Late components of median and ulnar SEPs (not shown) were also normal. Mechanical stimulation of the digits also resulted in $w$ shaped waveforms with correspondent negativities and positivities about 6 to $8 \mathrm{~ms}$ later and of smaller amplitudes when compared with components after direct electrical nerve stimulation at the wrist. This difference can be explained by the fact that mechanical finger pulses take additional receptor activation time, longer peripheral conduction time, and do not synchronise fast conducting I $\alpha$ fibres. Comparison of the waveforms of all five fingers showed some degree of abnormality in configuration and latency of the P50 component after stimulation of digit four and-less significant - of digit five.

\section{Discussion}

Radiculopathies exhibit characteristic clinical signs such as muscle weakness, irradiating pain, and sensory deficits along myotomal and dermatomal innervation zones of the affected spinal roots. Normal nerve conduction velocity often allows differentiation from peripheral postganglionic nerve disease. Cortical or spinal SEPs after electrical nerve stimulation have been reported as useful in the evaluation of radiculopathies by some authors, ${ }^{1011}$ but were considered of poor utility by others. ${ }^{1-3}$ Electrical dermatomal stimulation has been proposed, ${ }^{12}$ but again, doubt about its utility was raised both in lumbosacral ${ }^{1}$ and cervical radiculopathies. ${ }^{3}$ We also found normal early and late electrical SEPs from stimulation of mixed nerve trunks of the affected hand. We expected this result because median and ulnar nerve SEPs could be sufficiently conducted via intact $\mathrm{C} 6$ and $\mathrm{Th} 1$ roots in our case. Mechanical stimulation showed only minor abnormality in deficient dermatomes as indicated by poor configuration and delay of P50 particularly after stimulation of digit four compared with the intact thumb. By contrast, absence of LEPs after painful stimuli applied to affected dermatomes suggests considerable less intersegmental overlap of small diameter nociceptive afferents than large diameter mechanoreceptive afferents. This finding fits clinical experience of a narrow analgesic stripe as a typical feature of sensory loss in monoradiculopathy. ${ }^{13}$
Foerster, ${ }^{14}$ as early as 1936 , described greater caudo-oral extension of tactile dermatomes than pain dermatomes determined after surgical dissection of dorsal roots in patients treated for extreme spasticity. $\mathrm{He}$ also reported a case in which dissection of $\mathrm{C} 4$ and C5 dorsal roots only resulted in circumscribed thermanaesthesia and analgesia at the shoulder whereas tactile sensitivity remained intact. Inouye and Buchthal ${ }^{15}$ confirmed the existence of overlap of dermatomes between two to three spinal segments by recording spinal nerve potentials from electrodes inserted near cervical roots after electrical stimulation of various proximal and distal mixed nerves and sensory fibres in the upper limbs of healthy subjects. This case study supports Foerster ${ }^{14}$ by providing evidence that thin fibres of the pain and temperature system exhibit less intersegmental overlap than thick fibres of the tactile system. Although not considered of major importance for routine diagnostics in nerve root lesions, recording of LEPs may supplement standard examinations when objective documentation of the sensory disturbance is needed.

This work was supported by grants of the Deutsche Forschungsgemeinschaft. We gratefully acknowledge W Eickhoff for the EMG study.

1 Aminoff $M$, Goodin D, Barbaro NM, Weinstein PR Rosenblum ML. Dermatomal somatosensory evoked Rosenblum ML. Dermatomal somatosensory evoked potentials in unilateral

2 Aminoff M, Goodin D, Parry GJ, Barbaro NM, Weinstein PR, Rosenblum ML. Electrophysiologic evaluation of lumbosacral radiculopathies: electromyography, late responses, and somatosensory evoked potentials. Neurology 1985;35:1514-8.

3 Schmidt UD, Hess CW, Ludin HD. Somatosensory evoked potentials following nerve and segmental stimulation do not confirm cervical radiculopathy with sensory deficits. F Neurol Neurosurg Psychiatry 1988;51:182-7.

4 Bromm B, Treede RD. Laser evoked cerebral potentials in the assessment of cutaneous pain sensitivity in normal the assessment of cutaneous pain sensitivity in nom
subjects and patients. Rév Neurol 1991;147:625-43.

5 Bromm B, Frieling A, Lankers J. Laser evoked potentials in the assessment of disturbed pain and temperature sensithe assessment of disturbed pain and temperature sensi-
bility. Electroencephalogr Clin Neurophysiol 1991;80: bility. $284-91$.

6 Treede RD, Lankers J, Frieling A, Zangemeister WH, Kunze K, Bromm B. Cerebral potentials evoked by painful laser stimuli in patients with syringomyelia. Brain 1991;114:1595-607.

7 Biehl R, Treede RD, Bromm B. Pain ratings of short radian heat impulses. In: Bromm B, ed. Pain measurement in man. Amsterdam: Elsevier, 1984:397-408.

8 Desmedt JE, Huy NT, Bourguet M. The cognitive P40, $\mathrm{N} 60$ and P100 components of somatosensory evoked potentials and the earliest electrical signs of sensory processing in man. Electroencephalogr Clin Neurophysiol 1983; 56:272-82.

9 Hämäläinen $\mathrm{H}$, Kekoni J, Sams $M$, Reinikainen $\mathrm{K}$, Näätänen R. Human somatosensory evoked potentials to mechanical pulses and vibration: contributions of SI and SII somatosensory cortices to P50 and P100 compo
Electroencephalogr Clin Neurophysiol 1990;75:13-21.

10 Feinsod M, Blau D, Findler G. Somatosensory evoked potentials to peroneal nerve stimulation in patients with herniated lumbar discs. Neurosurgery 1982;11:506-1

11 Walk D, Fisher MA, Doundoulakis SH, Hemmati M Somatosensory evoked potentials in the evaluation of lumbosacral radiculopathy. Neurology 1992;42 1197-202.

12 Scarff TB, Dallmann DE, Toleikis JR, Bunch WH Dermatomal somatosensory evoked potentials in the diagnosis of lumbar root entrapment. Surg Forum 1981, 32:489-91.

13 Mumenthaler $M$, Schliack $H$. Läsionen peripherer Nerven. New York, Stuttgart: Georg Thieme Verlag, 1993.

14 Foerster $O$. Symptomatologie der Erkrankungen des Rückenmarks und seiner Wurzeln. In: Bumke $O$ Foerster $\mathrm{O}$, eds. Handbuch der Neurologie. Bd V. Berlin: Foerster O, eds. Hand

15 Inouye Y, Buchthal F. Segmental sensory innervation determined by potentials recorded from cervical spinal determined by potentials recorde 